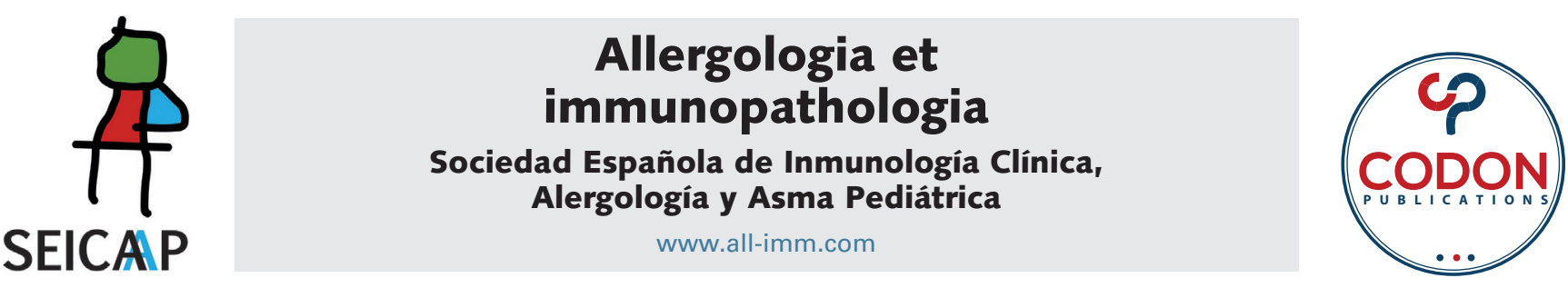

POINT OF VIEW

\title{
Rhinomanometry: point of care test (POCT) for allergic rhinitis in children?
}

\author{
Velia Maliziaa*, Giuliana Ferrante ${ }^{\mathrm{b}}$, Giovanna Cilluffo ${ }^{a}$, Salvatore Fasola ${ }^{a}$, \\ Laura Montalbano ${ }^{a}$, Stefania La Grutta ${ }^{a}$
}

\author{
anstitute for Biomedical Research and Innovation, National Research Council, Palermo, Italy \\ ${ }^{b}$ Department of Health Promotion, Mother and Child Care, Internal Medicine and Medical Specialties, University of Palermo, \\ Palermo, Italy
}

Received 7 April 2021; Accepted 14 May 2021

Available online 1 September 2021

\section{KEYWORDS \\ Allergic rhinitis; \\ rhinomanometry; \\ point of care test; \\ diagnostic \\ procedures; \\ children}

\begin{abstract}
Allergic rhinitis (AR) is a global health problem: its prevalence is $23 \%$ in Europe, although it is underestimated because as many as $45 \%$ of the cases remain undiagnosed. Globally, almost 500 million people suffer from AR, which shows its increasing incidences. The diagnostic course of AR is based on clinical history, supported by anterior rhinoscopy. This inspects the anterior part of the nasal cavity accompanied by allergic sensitivity tests (cutaneous allergic skin tests or specific immunoglobulin E levels). The availability of standardised diagnostic procedures is able to provide objective evaluations of inflammatory situation, and the degree of nasal obstruction may give an advantage in reducing the risk of underestimating the diagnosis of AR. Diagnostic tests with a high level of accuracy are able to provide immediate results, which can sustain the doctor in diagnostic-therapeutic framework. The development of Point of Care Tests (POCTs) could be a useful tool. Considering that nasal obstruction is the most common symptom in patients with AR, the rhinomanometry (RM) test is the most indicated objective evaluation for nasal obstruction. Several studies have also shown the practicability of such diagnostic techniques applied in children. So far, no study has evaluated whether all the applicable requirements are fulfilled by RM in order to be considered as a POCT. The purpose of this perspective was to assess whether all the POCT requirements are fulfilled by RM by conducting a narrative review of the existing literature in which RM has been used in the diagnosis and management of $A R$ in children. A few but encouraging results of studies on children supported the potential use of RM in the area of POCT. However, costs of instruments and the training of personnel involved remain to be explored. The studies support the potential use of RM in POCTs.
\end{abstract}

(c) 2021 Codon Publications. Published by Codon Publications.

*Corresponding author: Velia Malizia, Institute for Biomedical Research and Innovation, National Research Council, Palermo, Italy. Email address: velia.malizia@irib.cnr.it 


\section{Introduction}

Allergic rhinitis (AR) is a global health problem: its prevalence in Europe is estimated to be $23 \%$, although it is an underestimated number because as far as $45 \%$ of the cases remain undiagnosed. Globally, almost 500 million people suffer from AR, which shows its increasing prevalence. ${ }^{1}$ In $80 \%$ of cases, AR symptoms develop before the age of 20 years, and $40 \%$ of these cases already have symptoms before the age of 6 years. ${ }^{2}$

Allergic rhinitis is defined as an inflammation of nasal mucous and is characterised by at least two of the following symptoms: congestion/obstruction, rhinorrhea, sneezing and itching. ${ }^{3}$ AR symptoms have a significant effect on sleep, learning, school performance and overall well-being of children. Most of these problems are connected to poor quality of sleep, which leads to tiredness, reduction in vigilance, mood swings and cognitive dysfunction.

Allergic rhinitis has a huge economic and health burden: in fact, it has a strong impact on the patient's quality of life, cost of health care and economic productivity. In the context of Global Allergy and Asthma European Network (GALEN), Zuberbier et al. ${ }^{4}$ conducted a study between 2008 and 2011 on the analysis of direct and indirect global costs of allergic diseases in the European Union (EU), considering data from Eurostat and Eurofound. The evaluation was conducted on 15-65-year-old people. The total indirect costs (including absence from work and reduced productivity) of patients not treated appropriately varied between EUR55 and 151 billion annually. ${ }^{4}$

The diagnostic course of AR is based on clinical history, supported by anterior rhinoscopy (AnRh). This inspects the anterior part of the nasal cavity accompanied by allergic sensitivity tests (cutaneous allergic skin tests or specific immunoglobulin $\mathrm{E}$ [IgE] levels). ${ }^{3}$ The availability of standardized diagnostic procedures is able to provide objective evaluations of inflammatory situations, and the degree of nasal obstruction may be useful in reducing the risk of underestimating the diagnosis of AR. Diagnostic tests with a high level of accuracy are able to provide immediate results, which can sustain the doctor in diagnostictherapeutic framework. The development of Point of Care Tests (POCTs) could be a useful tool.

\section{Point of Care Tests: Definition and Characteristics}

The essential characteristics common to all the definitions of POCT include the following: (a) The context where the test could be performed (patient's home, community centre, surgery, laboratories, hospitals); (b) properties of the test (easily undertaken with an immediate result); and (c) economic sustainability. ${ }^{5}$

(a) Context where it is possible to perform the test

It is very important to define context where the test could be performed by either patients or authorised personnel (nurses, doctors, laboratory technicians etc.).

Point of care test could be carried out at different places:

Patient's home: It is possible for the patients to carry out the test themselves in the privacy of their own home.
Community centres: The test could be carried out by a doctor at community centres (hospitals, schools, barracks and hotels). The doctor could propose a medical consultation depending on test results.

Hospital outpatient departments or clinics: The tests could be carried out by doctors or nurses using portable instruments.

Laboratories: The tests could be performed using instruments requiring qualified personnel, such as laboratory technicians, who follow standard procedures.

Hospitals: The tests are performed by hospital personnel.

\section{(b) Characteristics of test}

The test must be rapid and easy to perform. The results must be available instantly, possibly at the same visit or within 24 hours. Object of the test must be to guide the drawing up of diagnosis and treatment.

(c) Economic sustainability

The POCT programme needs feasible business models to guarantee their sustainability in the socioeconomic context where they are used. It is very important, apart from technology, to understand the health system (public or private), country, and area (urban or rural) in which the test is introduced. It is also important to evaluate business models, taking into consideration the financial support, incentives and training courses.

\section{Point of Test Care in Allergic Rhinitis}

Gelardi et al. ${ }^{6}$ identified a diagnostic instrumental method in nasal cytology (NC) that could be used in the differential diagnosis of AR and in the longitudinal evaluation of inflammatory state of nasal mucous in adults. The authors underlined that this reliable, rapid and easy to perform test, at a low cost, has all the requisites to be defined as POCT.

Rhinomanometry (RM) and acoustic rhinometry are the most suitable tests for the objective evaluation of nasal obstruction. Acoustic rhinometry consists of an acoustic generator that generates acoustic waves transmitted through a tube into the nostril. The size and pattern of the reflected sound waves provide information on the structure and size of the nasal cavity, with the time delay of reflections correlated with the distance from the nostril. ${ }^{7}$ Acoustic rhinometry has been proved to be a sensitive and specific test for assessing surgery-induced changes in nasal cavities. ${ }^{8}$

Rhinomanometry is a functional assessment of airflow and includes the measurement of transnasal pressure and airflow. Considering that nasal obstruction is the most common symptom in patients with $A R, R M$ has been found to be a more sensitive and specific test than acoustic rhinometry for patients with functional nasal obstruction such as AR. ${ }^{8}$

Several studies have shown the practicability of such a diagnostic technique applied in children.9-12 So far, no study has evaluated whether all the applicable requirements are fulfilled by RM in order to be considered as a POCT.

The purpose of this perspective was to assess whether all the POCT requirements were fulfilled by RM by conducting a narrative review of the existing literature in which RM was used in the diagnosis and management of $A R$ in children. 


\section{Rhinomanometry}

Rhinomanometry is a functional aerodynamic nasal test which simultaneously measures the transnasal air flow and the degree of pressure between the rhinopharynx and the anterior part of the nose. A constant pressure of $150 \mathrm{~Pa}$ is used to calculate nasal resistance to measure the degree of nasal obstruction. ${ }^{11}$ At a pressure of $150 \mathrm{~Pa}$, reference values for different degrees of nasal obstruction symptoms estimated in terms of total nasal flow are known, corresponding to no obstruction $\left(>800 \mathrm{~cm}^{3} / \mathrm{s}\right.$ ), slight obstruction $\left(500-800 \mathrm{~cm}^{3} / \mathrm{s}\right)$, moderate obstruction $\left(300-500 \mathrm{~cm}^{3} / \mathrm{s}\right)$, severe obstruction $\left(100-300 \mathrm{~cm}^{3} / \mathrm{s}\right)$ and airway closed $\left(<100 \mathrm{~cm}^{3} / \mathrm{s}\right) .^{12}$

Following RM methods are used presently: (i) Anterior $\mathrm{RM}$, where the pressure detector is positioned in the nostril; (ii) Posterior RM, where the pressure detector is positioned in the posterior part of the oropharynx; and (iii) Post-nasal RM, where the pressure detector is positioned in the nasal-pharynx. The consent document of the International Committee for Standardising RM has established that the most physiological technique is the active anterior RM, defining it as the chosen method for measuring nasal ventilation where the air flow and the degree of pressure are measured through the left and right nostril during a normal breathing cycle.

Rhinomanometry can also sustain a diagnostic course and the monitoring of seasonal AR by evaluating nasal hyperactivity through nasal allergen provocation test (NAPT) and response to treatment. So far, few studies have investigated RM repeatability in children, whilst numerous studies have reported controversial results in adults. In a recent study conducted on 50 children with AR, Cilluffo et al. evaluated the repeatability and reproduction of RM parameters. This study put into evidence the reliability of this instrument, reporting an intra-class correlation coefficient (ICC), therefore showing that RM is an accurate and reliable diagnostic technique. ${ }^{9}$

\section{Does RM tool meet the requirement of "context where it is possible to perform the test?"}

According to a standardised procedure, to perform RM, the patient must be seated for $15 \mathrm{~min}$ in a temperature- and humidity-controlled room. Subsequently, a face mask is applied and the patient must breathe keeping the mouth closed. ${ }^{11}$

The registration is carried out during a normal breathing cycle and, as many studies have shown, it could be performed easily in the doctor's surgery. $.10,12-14$

\section{Does RM tool meet the requirement of "characteristics of test?"}

Rhinomanometry is an instrumental exam where the results are obtained in real time. Studies done by Chandra et $a .^{15}$ on an adult population have shown that the results of RM can be rapidly obtained in 20-30 min. Likewise, studies undertaken on children have shown that the test results can be rapidly obtained during the same visit, $, 10,12,14$ thus helping the doctor to make diagnosis and prescribe therapy.

\section{Diagnosis process}

Ciprandi et al. ${ }^{10}$ have highlighted the diagnostic support that RM offers, giving an objective evaluation of the inflammatory process at the base of nasal obstruction. The aim of this study, done on 20 children (mean age: $13.4+1.6$ years), was to investigate possible relationships between nasal symptoms, inflammatory cells, cytokines and nasal airflow in children with persistent AR because of mite sensitization. The levels of eosinophils (number of inflammatory cells) in this study were significantly higher in patients with severe obstructive symptoms compared with the levels of eosinophils in patients with mild symptoms [12.1 (SD 2.0) vs. 8.3 (SD 2.2), $P<0.001]$. Therefore, the number of eosinophils was significantly associated with the nasal flow [correlation coefficients $0.69, \mathrm{P}=0.0007$ ]. RM performed during the provocation tests with nasal allergens showed a valid support for the diagnosis of AR in patients with negative cutaneous and serological allergy tests. Zicari et al. ${ }^{16}$ conducted a study on 20 children with negative skin-prick test results and serum-specific immunoglobulin $\mathrm{E}$ (slgE) values. The patients underwent a provocation test using dust mites and graminaceae pollen. RM performed $15 \mathrm{~min}$ before and after NAPT showed a significant increase in the mean and standard deviation (SD) nasal resistance values examined by the anterior active rhinomanometry (AARM) $\left[1.30 \pm 0.47 \mathrm{Pas} / \mathrm{cm}^{3}\right.$ vs. $\left.2.23 \pm 1.33 \mathrm{Pas} / \mathrm{cm}^{3} ; \mathrm{P} \leq 0.001\right]$ in 12 patients with positive NAPT results. These data confirm the importance of RM in supplying objective information on the resistance of airways in children with AR and show the usefulness of this test in the evaluation of inflammatory state in children.

\section{Therapeutic process}

Apart from AR diagnosis, RM has a clinical relevance for reaching therapeutic choices, as shown in the study done on adult patients. ${ }^{10}$ Zicari et al. ${ }^{14}$ demonstrated RM validity as a support for therapeutic decisions in 60 children aged 6-10 years with persistent AR; these patients were randomized and divided into two groups, with 30 patients in each group. One group was treated with nasal budesonide and a saline isotonic solution for 2 weeks. The other group took saline isotonic solution only for 2 weeks. RM was performed on each child before and after the treatment. After 2 weeks of treatment, improvement was observed in nasal patency (\% of height-dependent paediatric reference value; $\Delta$ nasal patency $-26.13 \pm 25.25$ vs. $-11.83 \pm 11.31, \mathrm{P}<0.001)$. RM was also proved to be a valid support in the evaluation of obstruction change in the follow-up of children with $A R,{ }^{13}$ suggesting its important role in therapeutic choices.

\section{Does $R M$ tool meet the requirement o "economic sustainability?"}

Studies conducted by Chandra et al..$^{15}$ and Scadding et al. ${ }^{17}$ have put into evidence the high costs of the instruments 
required to perform RM. However, it is pointed out that compared with high costs, the advantages provided by RM in terms of accuracy and rapid results could guarantee its economic sustainability in the clinical management of patients with AR. In fact, correct diagnosis and appropriate therapy for these patients, especially considering the high health and social costs borne by an untreated disease, may be the basis for a favourable cost-benefit relationship.

\section{Conclusion}

The role of POCT is to speed up the diagnosis and guide doctor in reaching the most appropriate therapeutic decisions.

Point of Care tests are promising checks, but it is important to understand and identify principal obstacles in their use (costs, training of personnel, result communication, and socioeconomic environment where the tests are performed). Therefore, it is important to invest more in research and POCT programmes to develop and validate tests which are able to guarantee quality, sensibility and specificity

A few but encouraging studies done on children support the potential use of RM in the area of POCTs. However, costs of instruments and training of personnel remain to be explored.

\section{References}

1. Bauchau V, Durham SR. Prevalence and rate of diagnosis of allergic rhinitis in Europe. Eur Respir J. 2004 Nov;24(5):75864. https://doi.org/10.1183/09031936.04.00013904

2. Licari A, Ciprandi G, Marseglia A, Castagnoli R, Barberi S, Caimmi $\mathrm{S}$, et al. Current recommendations and emerging options for the treatment of allergic rhinitis. Expert Rev Clin Immunol. 2014 Oct;10(10):1337-47. https://doi.org/10.1586/17 44666X.2014.955476

3. Roberts G, Xatzipsalti M, Borrego LM, Custovic A, Halken S, Hellings PW, et al. Paediatric rhinitis: position paper of the European Academy of Allergy and Clinical Immunology. Allergy. 2013 Sep;68(9):1102-16. https://doi.org/10.1111/ all.12235

4. Zuberbier T, Lötvall J, Simoens S, Subramanian SV, Church MK. Economic burden of inadequate management of allergic diseases in the European Union: A GA(2) LEN review. Allergy. 2014 Oct;69(10):1275-9. https://doi.org/10.1111/all.12470

5. Pai NP, Vadnais C, Denkinger C, Engel N, Pai M. Point-ofcare testing for infectious diseases: Diversity, complexity, and barriers in low- and middle-income countries. PLoS
Med. 2012;9(9):e1001306. https://doi.org/10.1371/journal, pmed.1001306

6. Gelardi M, Landi M, Ciprandi G. The pragmatic role of nasal cytology: A point-of-care testing to implement precision medicine in clinical practice. Rev Alerg Mex. 2018 JulSep;65(3):259-63. https://doi.org/10.29262/ram.v65i3.373

7. Scadding G, Hellings P, Alobid I, Bachert C, Fokkens W, van Wijk RG, et al. Diagnostic tools in rhinology EAACI position paper. Clin Transl Allergy. 2011, Oct;1(1):2. https://doi. org/10.1186/2045-7022-1-2

8. Passàli D, Mezzedimi C, Passàli GC, Nuti D, Bellussi L. The role of rhinomanometry, acoustic rhinometry, and mucociliary transport time in the assessment of nasal patency. Ear Nose Throat J. 2000;79(5):397-400. https://doi. org/10.1177/014556130007900515

9. Cilluffo G, Zicari AM, Ferrante G, Malizia V, Fasola S, Duse M, et al. Assessing repeatability and reproducibility of Anterior Active Rhinomanometry (AAR) in children. BMC Med Res Methodol. 2020 Apr 17;20(1):86. https://doi.org/10.1186/ s12874-020-00969-1

10. Ciprandi G, Marseglia GL, Klersy C, Tosca MA. Relationships between allergic inflammation and nasal airflow in children with persistent allergic rhinitis due to mite sensitization. Allergy. 2005 Jul;60(7):957-60. https://doi. org/10.1111/j.1398-9995.2005.00664.x

11. Vogt K, Jalowayski AA, Althaus W, Cao C, Han D, Hasse W, et al. 4-Phase-rhinomanometry (4PR)-Basics and practice 2010. Rhinol Suppl. 2010;21:1-50.

12. Chen IC, Lin YT, Hsu JH, Liu YC, Wu JR, Dai ZK. Nasal airflow measured by rhinomanometry correlates with FeNO in children with asthma. PLoS One. 2016 Oct 28;11(10):e0165440. https://doi.org/10.1371/journal.pone.0165440

13. Priftis KN, Drigopoulos K, Sakalidou A, Triga M, Kallis V, Nicolaidou P. Subjective and objective nasal obstruction assessment in children with chronic rhinitis. Int J Pediatr Otorhinolaryngol. 2006 Mar;70(3):501-5. https://doi. org/10.1016/j.ijporl.2005.07.027

14. Zicari AM, Occasi F, Montanari G, Indinnimeo L, De Castro G, Tancredi $G$, et al. Intranasal budesonide in children affected by persistent allergic rhinitis and its effect on nasal patency and Nasal Obstruction Symptom Evaluation (NOSE) score. Curr Med Res Opin. 2015 Mar;31(3):391-6. https://doi.org/10.1185/0 3007995.2015.1009532

15. Chandra RK, Patadia MO, Raviv J. Diagnosis of nasal airway obstruction. Otolaryngol Clin North Am. 2009 Apr;42(2):20725, vii. https://doi.org/10.1016/j.otc.2009.01.004

16. Zicari AM, Occasi F, Di Fraia M, Mainiero F, Porzia A, Galandrini R, et al. Local allergic rhinitis in children: Novel diagnostic features and potential biomarkers. Am J Rhinol Allergy. 2016 Sep;30(5):329-34. https://doi.org/10.2500/ajra.2016.30.4352

17. Scadding G, Hellings P, Alobid I, Bachert C, Fokkens W, van Wijk RG, et al. Diagnostic tools in rhinology EAACl position paper. Clin Transl Allergy. 2011 Jun 10;1(1):2. https://doi. org/10.1186/2045-7022-1-2 